\title{
Study of ergot isolation from rye in an aqueous salt solution
}

\author{
Viktor Saitov ${ }^{1,2 *}$, Vyacheslav Farafonov ${ }^{2}$, Aleksey Saitov ${ }^{2}$ \\ ${ }^{1}$ Federal Agrarian Scientific Center of the North-East, 166 A, Lenin str., Kirov, 610007, Russia \\ ${ }^{2}$ Vyatka State Agricultural Academy, 133, October ave., Kirov, 610017, Russia
}

\begin{abstract}
The aim of the research is to determine the effectiveness of ergot isolation and to estimate grain losses in waste when the cereal material is immersed in the stream material in water and an aqueous solution of salt of different densities $\rho$ zh from the specific grain load gsp. Practical experiments were carried out by feeding grain material of winter rye of Falenskaya 4 variety with a moisture content of $14 \%$ from a height of $\mathrm{h}=60 \cdot 10-3 \mathrm{~m}$ into water and an aqueous solution of sodium chloride $(\mathrm{NaCl})$ with a density of $1030,1060,1090,1120,1150$ and $1180 \mathrm{~kg} / \mathrm{m} 3$. The variation of the specific grain load gsp was carried out according to the values of $0.674 ; 1.469 ; 2,871 ; 4.449$ and $7.221 \mathrm{~kg} /(\mathrm{s} \cdot \mathrm{m})$, which corresponded to the opening of the outlet window of the bunker of the experimental setup $10.0 ; 15.0 ; 20.0 ; 25.0$ and $30.0 \cdot 10-3 \mathrm{~m}$. The temperature of ambient air, water and an aqueous solution of salt was 200C. It has been established that the density pzh of an aqueous salt solution has a greater influence on the result of the technological process than the specific grain load gsp. At a density $\rho$ zh of the aqueous solution of the salt of $1150 \mathrm{~kg} / \mathrm{m} 3$, there is a $100 \%$ emergence of ergot sclerotia on the surface of the solution, and the losses of the PZ grain to the waste do not exceed 2,52\%, which corresponds to the agrotechnical requirements for the final grain cleaning machines.
\end{abstract}

\section{Introduction}

Grain is the oldest food product of people, subsequently with the development of labor productivity and its sufficient production - feed for farm animals.

The grain heap delivered from combine harvesters $[1,2,3]$ to the post-harvest processing points contains, in addition to high-grade grain, also weedy and harmful impurities, which include ergot sclerotia $[4,5]$.

The use of air and screen indented surface separator, pneumatic sorting tables, photo separators and other devices does not give positive results when cleaning grain material from ergot due to the closeness of its properties and the properties of the culture being cleaned $[6,7,8,9,10,11,12]$.

Ergot sclerotia, which are toxic impurities in the grain material $[13,14,15]$, have a lower density than that of the grain of cultivated plants. Therefore, to isolate ergot sclerotia

\footnotetext{
"Corresponding author: vicsait-valita@e-kirov.ru
} 
from rye seeds, one can use aqueous solutions of inorganic salts, for example, sodium chloride or potassium salt.

For the mechanization of the allocation of ergot sclerotia from rye seeds in a wet way, an urgent issue is the development of a device for cleaning grain material [16].

When developing a device for cleaning grain material by density using the wet method, it is necessary to determine the efficiency of ergot sclerotia isolation and identification of grain losses in waste during in-line immersion of grain material in an aqueous salt solution depending on the specific grain load $g_{s p}$ at different density $\rho_{z h}$ of the solution.

\section{Materials and methods}

To achieve this goal, practical experiments were carried out on the stream of winter rye grain Falenskaya 4 with a moisture content of $14 \%$ from a height of $h=60 \cdot 10^{-3} \mathrm{~m}$ [17] into water and an aqueous solution of sodium chloride $(\mathrm{NaCl})$ of various densities $\rho_{z h}[18,19]$. The cereal material consisted of 10000 winter rye grains and 1000 ergot sclerotia. To study the process of separating grain material into fractions in an aqueous salt solution, an experimental setup was made. A general view of this installation is shown in Figure 1, and its technological scheme is presented in Figure 2

The experimental setup for studying the grain stream immersion in an aqueous salt solution consisted of a laboratory tripod 1, hopper 3, tank 6 , mesh 8 for removing grains floating on the surface of the solution, and sieve 7 to separate the grains from the salt solution. The laboratory tripod consists of a stand and a vertical rack. It is additionally equipped with a counterbalance 9 for stability. The holder 2 is mounted on a vertical rack using a coupling with clamping screws, on which the hopper 3 is suspended.

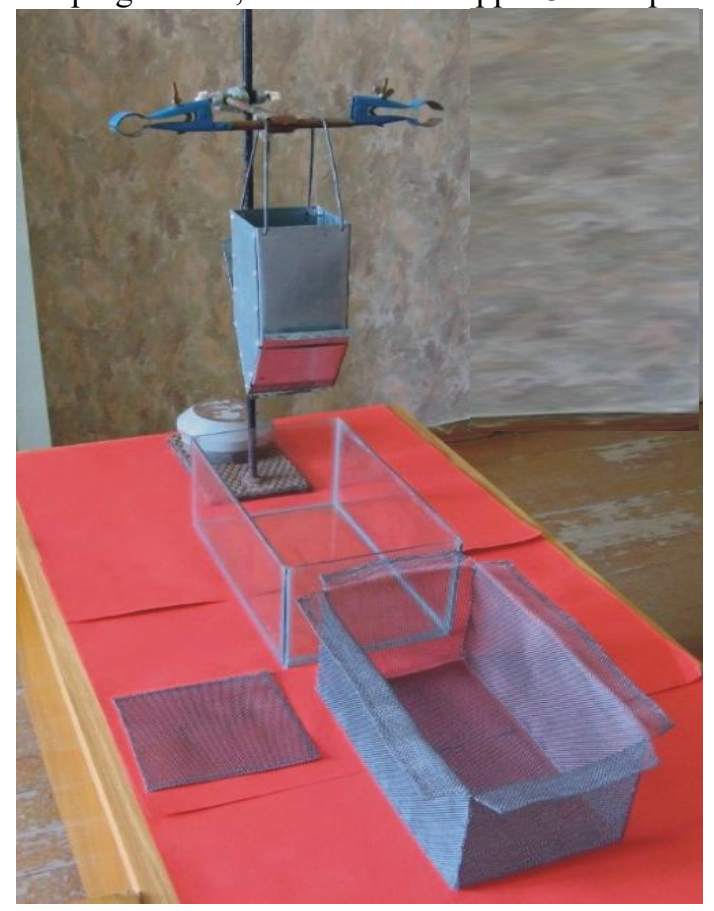

Fig. 1. General view of an experimental setup for studying the grain stream immersion in an aqueous salt solution 


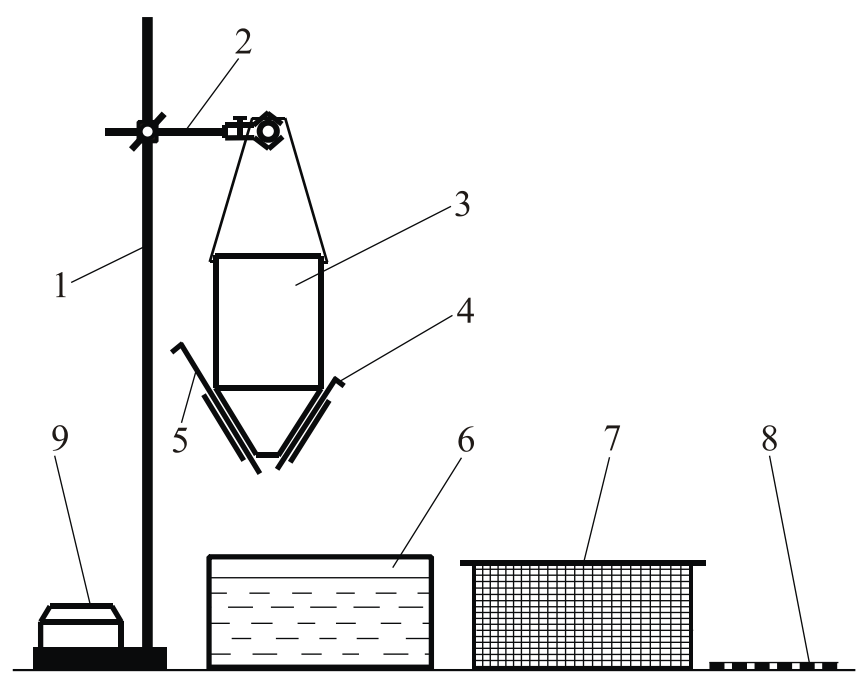

Fig. 2. Technological scheme of an experimental setup for studying the grain stream immersion in an aqueous salt solution: 1 - laboratory tripod; 2 - holder; 3 - hopper; 4 - control gate; 5 - inclined plane; 6 - tank; 7 - sieve; 8 - mesh; 9 - counterweight

The hopper 3 [20] consists of vertical side, back and end walls, and inclined bottom. The end wall at the level of the shoulder of the vertical back wall and the inclined bottom is mated with an additional inclined bottom equipped with an outlet opening and a control gate. The inclined bottom from the outlet opening is made in the form of an inclined plane 5 . The hopper 3 is made with side dimensions of $0.1 \mathrm{~m}$ and a height of $0.23 \mathrm{~m}$. The angle of inclination of the bottom and the additional bottom equipped with the outlet opening was $60^{\circ}$. The capacity of the hopper 3 , under which the tank 6 is set, allowed holding $1.5 \mathrm{~kg}$ of grain.

The tank 6 made of transparent glass, the side walls and the bottom of which are glued together with a silicone-based sealant, is a glass vessel with a length of $0.35 \mathrm{~m}$, a width of $0.20 \mathrm{~m}$, and a height of $0.15 \mathrm{~m}$. The volume of the water or salt solution poured in this vessel was 9 liters.

To remove grains floating on the surface of the solution, a metal mesh 8 was used with mesh openings of $1.2 \cdot 10^{-3} \mathrm{~m}$, which was made square in shape with a side size of $0.15 \mathrm{~m}$.

The sieve 7 for separating grains from the salt solution is a colander made of a metal mesh with mesh openings of $1.2 \cdot 10^{-3} \mathrm{~m}$. The external dimensions of the sieve 7 corresponded to the internal dimensions of the tank 6 . The walls of the sieve 7 are equipped with small "ears" that fix this device on top of the tank 6.

The process of studying the separation of grain material into fractions when immersed in a stream of an aqueous salt solution is as follows. From above, the grain material is loaded into the storage part of the hopper 3 from the stream, from which it is uniformly distributed across the width of the outlet opening into the bath 6 with an aqueous salt solution in which the sieve 7 is preliminarily placed. When the grain material enters the aqueous salt solution, "heavy" grains having large the density compared with the density of the solution, sink to the bottom of the bath 6 , and "light" grains and sclerotia ergot with a lower density float to the surface of the salt solution. During visual observation of the process of immersion of grain material by a stream in an aqueous solution of salt, it was noticed that some sclerotia of ergot and grains with a lower density than the density of the solution are captured by sinking "heavy" grains and held by them at the bottom of the bath 6. Therefore, 6 grains settled on the bottom of the bath ergot sclerotia was forcibly mixed with a glass rod. As a result of this, the retention of "heavy" grains of ergot sclerotia and 
"light" grains, which then float to the surface of an aqueous salt solution, is eliminated. Sclerotia of ergot and grains, which appeared on the surface of an aqueous salt solution, are removed by a grid 8 to calculate their number.

"Light" grains, which appear on the surface of an aqueous salt solution and are disposed of as waste, are usually puny, have external and internal microdamages, and are therefore least valuable in terms of biological properties. These grains will have poor germination and do not represent value as a seed material and as a grain for germination upon receipt of high-quality malt.

Removing sieve 7 from bath 6, the drowned grain is filtered from an aqueous solution of salt and laid out to dry. The sieve 7 is again placed in the bath 6 and the process of studying the separation of grain material into fractions when immersed in a stream of salt in an aqueous solution is repeated with varying specific gravity $g_{s p}$ and density of the solution $\rho_{z h}$. Variation of the specific load $g_{s p}$ of the outflow of grain material from the hopper 3 is carried out by adjusting the shutter 4 by changing the bore of the outlet of the hopper 3 . The height $h$ of the supply of grain material relative to the surface of the salt solution is set by changing the position of the hopper 3 by moving the sleeve with holder 2 along the height of the vertical rack of the laboratory tripod 1 .

The proportion of isolated ergot sclerotia was determined by the formula (\%) [21]:

$$
R_{S}=\frac{n_{6}}{n_{5}} \cdot 100
$$

where $n_{5}$ - the number of ergot sclerotia fed into water and an aqueous solution of salt, $n_{5}=1000 \mathrm{pcs}$;

$n_{6}$ - the number of ergot sclerotia on the surface of water or an aqueous solution of salt, pcs.

The proportion of non-drowned grains, even with forced exposure to them, which constitute the loss of grain to waste, is determined by the formula (\%) [21]:

$$
P_{Z}=\frac{n_{4}}{n_{1}} \cdot 100
$$

where $n_{1}$ - the number of grains of salt supplied to the aqueous solution, $n_{1}=10000 \mathrm{pcs}$;

$\mathrm{n}_{4}$ - the number of grains on the surface of an aqueous salt solution, which did not drown even with forced exposure to them, pcs.

To obtain more reliable information, experiments on immersion of grain in water and an aqueous solution of salt were carried out in triplicate. The temperature of air, water and an aqueous solution of salt was $20^{\circ} \mathrm{C}$. The variation of the specific grain load $g_{s p}$ was carried out with values of $0.674 ; 1.469 ; 2.871 ; 4.449$ and $7.221 \mathrm{~kg} /(\mathrm{s} \cdot \mathrm{m})$. This corresponded to the opening of the outlet window of the bunker of the experimental setup $10.0 ; 15.0 ; 20.0 ; 25.0$ and $30.0 \cdot 10^{-3} \mathrm{~m}$. Processing of the obtained experimental data was carried out on a personal computer using a special program for the statistical processing of information SigmaPlot 11.

\section{Results and Discussion}

The results of experiments on the immersion of the grain material of winter rye of the Falenskaya 4 variety in water and an aqueous solution of sodium chloride $(\mathrm{NaCl})$ of different density $\rho_{z h}$ with varying specific grain load $g_{s p}$ are shown in Figure 3 and in Figure 4. 


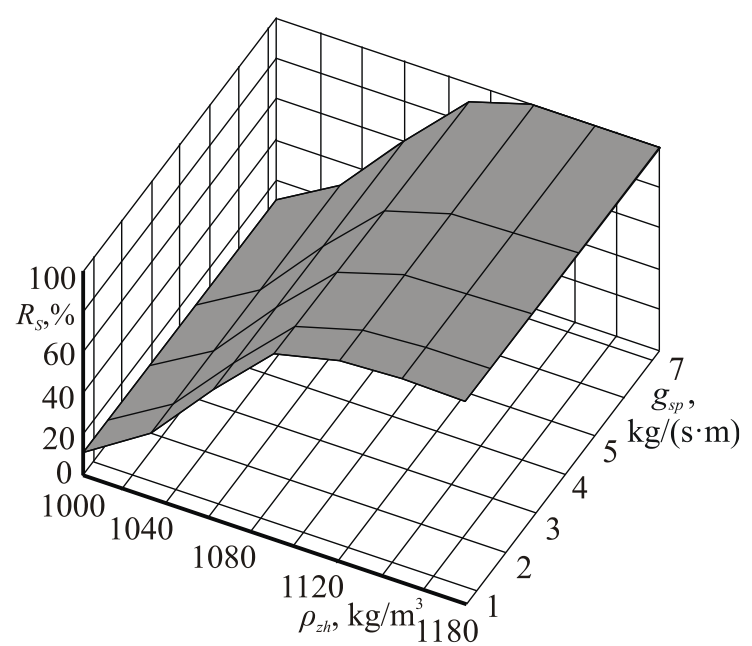

Fig. 3. Dependence of the proportion of $R_{S}$ of isolated ergot sclerotia when a stream of grain material of winter rye of the Falenskaya 4 variety is immersed in water and an aqueous solution of sodium chloride $(\mathrm{NaCl})$ of different densities $\rho_{z h}$ with varying specific grain load $g_{s p}$

The dependence of the proportion of $R_{S}$ of isolated ergot sclerotia upon immersion in a stream of water and an aqueous solution of sodium chloride of winter rye grain material of the Falenskaya 4 variety on the specific grain load $g_{s p}$ at different density $\rho_{z h}$ of the solution is described by the equation (\%):

$$
R_{S}=-5017.0481+8.8232 \rho_{z h}+0.0822 g_{s p}-0.0038 \rho_{z h}^{2}-0.0075 g_{s p}^{2} .
$$

From the obtained equation (3), it follows that the density $\rho_{z h}$ of an aqueous salt solution has a greater influence on the $R_{S}$ indices than the specific grain load $g_{s p}$. The reliability of the obtained regression model is expressed by small deviations of the actual values from the calculated $\left|R_{S_{-}} \bar{R}_{S}\right|$, components $0.7695 \ldots 9.0654 \%$. The arithmetic average of three experiments is taken as the actual value. The multiple coefficient of determination of $R^{2}$ (Rsqr) is 0.98 and is close to 1.0. This shows that the regression model explains almost all the variability of $R_{S}$ from the variables $\rho_{z h}$ and $g_{s p}$. In this case, the adjusted multiple coefficient of determination $R_{S}^{2}$ (Adj Rsqr) shows that $97.54 \%$ of the variation of the function $R_{S}=f\left(\rho_{z h}, g_{s p}\right)$ is explained by the variation of its variables, so we can consider the resulting model of good quality. The standard error of the estimate (Standard Error of Est.) of the regression model is 5.511 and it is 2.45 times smaller than the standard error of the estimate (Standard Error of Est.) of the linear model, equal to 13.4960. Accordingly, in this case, a nonlinear model is preferable. The Durbin-Watson statistic is 0.444 , which is greater than zero, but less than 2, and therefore autocorrelation between the experimental data is in question. The calculated value of the $F$-criterion of Fisher (F), equal to 337.5304, is 125.476 times larger than the tabular value, which for the significance level of 0.05 and the number of degrees of freedom (DF) $k_{1}=4, k_{2}=30$ is 2.69 (Fcalc. $>$ Ftab.). This means that the explained variance is significantly larger than the unexplained, and the regression model as a whole is significant. Consequently, the obtained regression model (3) adequately describes the real process, and therefore it is significant and informationally capable of characterizing the presence of $R_{S}$ ergot sclerotia on the surface of water and an aqueous solution of salt during in-line immersion of grain material.

The response surface (Figure 3) shows that when the grain material is immersed in water 
$\left(\rho_{z h}=1000 \mathrm{~kg} / \mathrm{m}^{3}\right)$, the percentage of $R_{S}$ of ergot sclerotia on average is no more than $10.2 \%$. An increase in the density $\rho_{z h}$ of an aqueous salt solution increases the percentage of the proportion of $R_{S}$ in the release of ergot sclerotia. So, at a density $\rho_{z h}$ of an aqueous salt solution of 1030 and $1060 \mathrm{~kg} / \mathrm{m}^{3}$, the average $R_{S}$ values are 28.7 and $60.6 \%$, respectively. A significant increase in the proportion of $R_{S}$ of ergot sclerotia emission occurs with an increase in the density $\rho_{z h}$ of an aqueous salt solution from 1090 to $1120 \mathrm{~kg} / \mathrm{m}^{3}$, at which the average $R_{S}$ values are 90.4 and $98.3 \%$, respectively. At a density $\rho_{z h}$ of an aqueous salt solution of $1150 \mathrm{~kg} / \mathrm{m}^{3}, 100 \%$ eruption of ergot sclerotia to the surface of the solution occurs. A further increase in the density $\rho_{z h}$ of an aqueous salt solution causes only a guaranteed release of all ergot sclerotia.

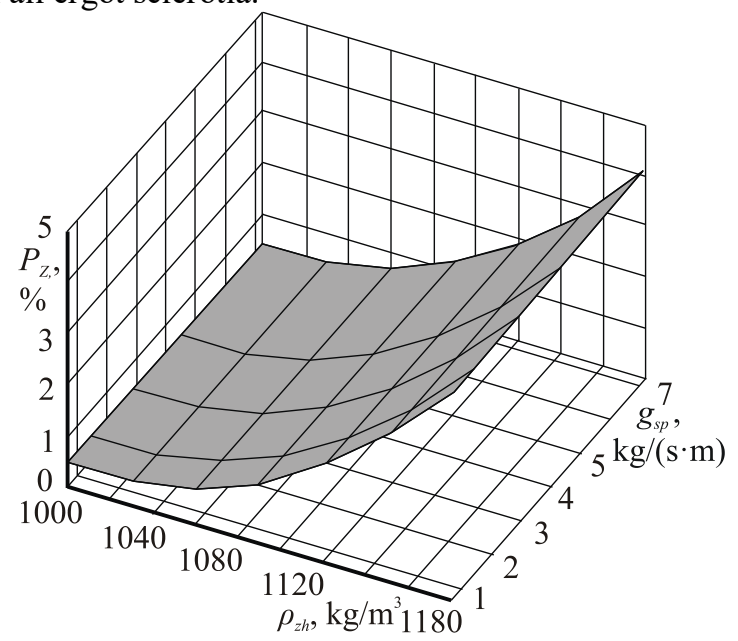

Figure 4. Dependence of the loss of grain $P_{Z}$ in waste when a stream of the grain material of winter rye of the Falenskaya 4 variety is immersed in water and an aqueous solution of sodium chloride $(\mathrm{NaCl})$ of different densities $\rho_{z h}$ with varying specific grain load $g_{s p}$

The dependence of the loss of $P_{Z}$ of grain in the waste when immersed in a stream of water and an aqueous solution of sodium chloride of winter rye grain material of the Falenskaya 4 variety on the specific grain load $g_{s p}$ at different density $\rho_{z h}$ of the solution is described by the equation (\%):

$$
P_{Z}=137.4158-0.2699 \rho_{z h}+0.0018 g_{s p}+0.0001 \rho_{z h}^{2}-0.0002 g_{s p}^{2} \text {. }
$$

From equation (4), it follows that the density of grain water in the waste is significantly affected by the density $\rho_{z h}$ of an aqueous solution of salt, the specific grain load $g_{s p}$ practically does not affect the parameters of the $P_{Z}$. Reliability of the regression model is expressed by small deviations of actual values from the calculated $\left|P_{Z}-\bar{P}_{Z}\right|$, components modulo $0.061 \ldots 0.337 \%$. The multiple correlation coefficient $R^{2}$ (Rsqr) is 0.97 , and is close to 1.0. This shows that the regression model explains almost all the variability of the $P_{Z}$ from the variables $\rho_{z h}$ and $g_{s p}$. In this case, the adjusted multiple coefficient of determination $P_{Z}^{2}$ (Adj Rsqr) shows that $96.89 \%$ of the variation of the function $P_{Z}=f\left(\rho_{z h}\right.$, $\left.g_{s p}\right)$ is explained by the variation of its variables, therefore, we can consider the resulting model of good quality. The standard error of the estimate (Standard Error of Est.) of the regression model does not exceed 0.230, and it is 2.1 times smaller than the standard error of the estimate (Standard Error of Est.) of the linear model, equal to 0.488. Therefore, a nonlinear model for describing the process is preferable, the standard error of estimation (Standard Error of Est.) of which is close to zero, which indicates the accuracy of the 
regression model. The Durbin-Watson statistic is 0.391 , which is greater than zero, but less than 2, and therefore autocorrelation between the experimental data is in question. The calculated value of the $F$-criterion of Fisher (F), equal to 265.4796, is 98.691 times greater than the tabular value, which for the significance level of 0.05 and the number of degrees of freedom (DF) $k_{1}=4, k_{2}=30$ is 2.69 (Fcalc. $>$ Ftab.). This means that the explained variance is significantly larger than the unexplained, and the regression model as a whole is significant in quality and its parameters. Accordingly, the obtained regression model (4) adequately describes the real process, and therefore it is significant and informationally capable of characterizing the presence of a non-drowned grain $P_{Z}$ on the surface of an aqueous solution of salt during continuous immersion of grain material, even forcibly.

From the response surface shown in Figure 4, it follows that the loss of $P_{Z}$ of grain in waste when immersed in water $\left(\rho_{z h}=1000 \mathrm{~kg} / \mathrm{m}^{3}\right)$ is on average $0.25 \%$, with a density of $\rho_{z h}$ of an aqueous salt solution of 1030,1060 and $1090 \mathrm{~kg} / \mathrm{m}^{3}$ average $P_{Z}$ values are 0.67 , 0.84 , and $1.25 \%$, respectively. With the values of the density of the aqueous salt solution $\rho_{z h}$ $=1120$ and $1150 \mathrm{~kg} / \mathrm{m}^{3}$, the loss of the surface area of the grain in the waste increases to 1.75 and $2.52 \%$, which is associated with an increase in the surface tension coefficient of the aqueous salt solution. The loss of $P_{Z}$ of grain to waste at a density of an aqueous salt solution $\rho_{z h}=1180 \mathrm{~kg} / \mathrm{m}^{3}$ is $4.32 \%$, which does not exceed the agrotechnical requirements for final grain cleaning machines.

\section{Conclusion}

Thus, based on the studies of the separation of the grain material of winter rye of the Falenskaya 4 variety with a moisture content of $14 \%$ into fractions when immersed in a stream of water and an aqueous solution of sodium chloride $(\mathrm{NaCl})$ at a temperature of $20^{\circ} \mathrm{C}$ with a feed height of $h=60 \cdot 10^{-3} \mathrm{~m}$, that a significant influence on the technological process is exerted by the density $\rho_{z h}$ of an aqueous salt solution, and the specific grain load $g_{s p}$ practically does not affect the fractionation indices of the grain material. At a density $\rho_{z h}$ of an aqueous salt solution of $1150 \mathrm{~kg} / \mathrm{m}^{3}$, ergot sclerotia emerges $100 \%$ to the surface of the solution, and the loss of $P_{Z}$ of grain to waste does not exceed $2.52 \%$, which corresponds to the agrotechnical requirements for final grain cleaning machines.

\section{Acknowledgement}

The study was carried out according to the scientific theme "Creating a machine for the exclusion of poisonous impurities (ergot sclerotia) from winter rye grain by specific mass using aqueous solutions of inorganic salts" according to research work No. 0767-2019-0094 "Creating innovative technologies and new generation technologies for mechanization of crop production and animal husbandry, adapted to the climatic conditions of the North-East of the European part of Russia" under section 10.9, subsection 162 of the Program of fundamental scientific research of State Academies of Sciences for 2013-2020.

\section{References}

1. N. Aldoshin, O. Didmanidze et al., Engineering for Rural Development: Proceedings of 18th International Scientific Conference. 18, 100-104 (2019) DOI: http://doi.org/10.22616/ERDev2019.18.N110

2. N. Aldoshin, O. Didmanidze Research in Agricultural Engineering.64(4) 209-214 (2018) DOI: http://doi.org/10.17221/107/2017-RAE 
3. V.I. Orobinsky, A.M. Gievsky et al., Advances in Engineering Research. 870-874 (2018)

4. L.M. Schekleina, T.K. Sheshegova Teoreticheskaya i prikladnaya ehkologiya.1, 5-12 (2013). DOI: http://doi.org/10.25750/1995-4301-2013-1-005-012 (In Russ.)

5. L.M. Schekleina Agrarnaya nauka Yevro-Severo-Vostoka, 20(2), 134-143 (2019). DOI: https://doi.org/10.30766/2072-9081.2019.20.2. 134-143 (In Russ.)

6. V.I. Orobinsky, A.P. Tarasenko, et al., Advances in Engineering Research. 849-852 (2018) DOI: 10.2991/agrosmart-18.2018.159

7. I. Badretdinov, S. Mudarisov et al., Journal of Applied Engineering Science. 4(17), 529-534 (2019) DOI: https://doi.org/10.5937/jaes17-22640

8. A.M. Gievsky, V.A. Gulevsky, V.I. Orobinsky Vestnik Moskovskogo gosudarstvennogo agroinzhenernogo universiteta imeni V.P. Goryachkina, 3(85), 1216 (2018). DOI: https://doi.org/10.26897/1728-7936-2018-3-12-16

9. P. Savinyh, Y. Sychugov et al., Engineering for Rural Development: 17th International Scientific Conference Engineering for Rural Development, Proceedings. 124-130 (2018). DOI: https://doi.org/10.22616/ERDev2018.17.N156

10. A.M. Gievsky, V.I. Orobinsky et al., IOP Conference Series: Materials Science and Engineering 327, $042035 \quad$ (2018). DOI: https://doi.org/10.1088/1757$899 X / 327 / 4 / 042035$

11. V.E. Saitov, R.F. Kurbanov, A.N. Suvorov. Procedia Engineering. 150, 107-110 (2016) DOI: https://doi.org/10.1016/j.proeng.2016.06.728

12. V.E. Saitov, V.G. Farafonov et al., IOP Conference Series: Materials Science and Engineering. 473, 012009 (2018). DOI: https://doi.org/10/1088/1757$899 \mathrm{X} / 457 / 1 / 012009$

13. L.M. Schekleina, T.K. Sheshegova Vestnik Mariyskogo gosudarstvennogo universiteta, 2(14), 83-90 (2018). DOI: https://doi.org/10.30914/2411-9687-2018-4-283-89

14. T.K. Sheshegova, L.M. Schekleina et al., Mikologiya i fitopatologiya, 53(3), 177-182 (2019) DOI: https://doi.org/10.1134 / S0026364819030127 (In Russ.)

15. T.K. Sheshegova, L.M. Schekleina, E.I. Utkina Agrarnaya nauka Yevro-SeveroVostoka 65(4), 30-35 (2018). DOI: https://doi.org/10.30766 / 20729081.2018.65.4.30-351 (In Russ.)

16. K.D. Astanakulov, Y.Z. Karimov, G. Fozilov AMA, Agricultural Mechanization in Asia, Africa and Latin America. 42(4), 37-40 (2011)

17. V.E. Saitov, V.G. Farafonov, A.V. Saitov IOP Conference Series: Earth and Environmental Science. 341, 012123 (2019). DOI: https://doi.org/10.1088/1755$1315 / 341 / 1 / 012123$

18. V.A. Sysuev, V.E. Saitov et al., Russian Agricultural Sciences. 43(3), 273-276 (2017). DOI: https://doi.org/10.3103/S1068367417030156

19. V.A. Sysuev, V.E. Saitov et al., Inzhenernyye tekhnologii i sistemy, 29(2), 248-264 (2019) DOI: https: //doi.org/10.15507/2658-4123.029.201902.248-264 (In Russ.)

20. V. Saitov, V. Farafonov, A. Suvorov, A. Saitov [Bunker for bulk materials]. Patent RF no. 2631556, 2017.

21. V. Saitov, R. Kurbanov, A. Saitov, IOP Conference Series: Earth and Environmental Science, 403, 012160, (2019) DOI: https://doi.org/10.1088/1755-1315/403/1/012160 